\title{
Cultura e Desempenho Organizacional: um Estudo Empírico em Empresas Brasileiras do Setor Têxtil
}

\author{
Neusa Maria Bastos Fernandes dos Santos
}

\section{RESUMO}

A importância estratégica da cultura organizacional tem sido sugerida e estudada por diferentes autores. Neste trabalho tem-se como principal objetivo explorar o impacto da cultura organizacional no desempenho da empresa. A pesquisa foi conduzida em quatro Estados do Brasil, com 478 indivíduos do corpo gerencial, participantes de 13 empresas brasileiras do setor têxtil. Quanto ao enfoque metodológico, optou-se por linha de investigação mais quantitativa: este tipo de análise requer o exame de múltiplas organizações para serem comparadas. A coleta de dados realizou-se por meio de questionário estruturado, com apoio estatístico de várias técnicas, entre elas a análise de clusters. Os resultados encontrados apontam para duas direções: a cultura está significativamente associada ao desempenho organizacional; as empresas com cultura forte evidenciam melhor desempenho.

Palavras-chaves: organizações; cultura organizacional; desempenho organizacional.

\begin{abstract}
This paper studies the impact of the organizational culture on the performance of different organizations according to evaluations made through accounting indices. The sample comprises 478 executive officers representing the management staff of thirteen textile companies of the spinning sector. The theoretical reference used for identifying the cultural profiles of the companies researched was based on the competing value model. Data gathered were submited to quantitative and statistical analyses. The results led to the following conclusions: the group of organizations sampled is basically characterized by two cultural profiles: strong cultures and weak cultures. Cultural strenght significantly correlates with organizational performance, i. e., companies with a stronger culture show a better performance than organizations with a weak culture. The Competing Value Model used proved adequate for measuring the cultural profiles and was found to be a valid and reliable data collecting instrument.
\end{abstract}

Key words: organizations; organizational culture; organizational performance. 


\section{INTRODUÇÃO}

A importância estratégica da cultura organizacional tem sido sugerida e estudada por diferentes autores, entre eles Peters e Watermann (1982), Deal e Kennedy (1982), Denison (1984), Cameron e Freemann (1990) e Yeung, Brockbank e Ulrich (1991), os quais argumentam que o desempenho organizacional é resultante dos diferentes tipos de cultura e da intensidade da força cultural apresentados pela empresa.

O interesse pelo estudo da cultura organizacional tem origem no final dos anos 80. Na base deste interesse, dá-se a tomada de consciência por parte de teóricos e praticantes da importância dos fatores culturais nas práticas de gestão e a crença no fato de a cultura constituir fator de diferenciação das empresas bem sucedidas.

É interessante observar que existem duas direções que os estudos empíricos têm seguido, ao examinarem as relações entre cultura organizacional e desempenho organizacional. A primeira delas trata a cultura como variável independente; o desempenho é visto como variável dependente. É nesta abordagem que esta pesquisa se enquadra, bem como os trabalhos de Peters e Watermann (1982), Denison (1984), Gordon (1985), entre outros. A segunda reverte a ordem da casualidade; então o pesquisador passa a assumir que o nível de desempenho, variável independente, é fator determinante dos atributos da cultura organizacional, variável dependente. O estudo de Martin, Anyrtsdin e Siehl (1988) é um exemplo desta linha de pesquisa. Os resultados obtidos, no entanto, mostraram pouco apoio para tal argumento.

Acadêmicos, em geral, têm identificado um conjunto de dimensões da cultura que em muito ajudam a organizar os atributos fundamentais do conceito, tais como:

- força cultural (poder de controlar o comportamento);

- congruência cultural (similaridade entre os elementos culturais);

- tipo cultural (atributos dominantes);

- continuidade cultural (consistência mantida ao longo do tempo);

- individualidade cultural (caráter singular de cada cultura);

- clareza cultural (como a cultura é definida, entendida e transmitida aos seus membros). 
Muitos autores, entre eles Sathe (1983), Schall (1983) e Schein (1984), argumentam que a força e a congruência de uma cultura são as suas principais dimensões. Uma cultura forte, congruente e que embasa a estrutura e as estratégias organizacionais é mais eficaz do que aquela fraca e incongruente.

Este trabalho foi delineado com o objetivo de explorar o impacto da cultura organizacional no desempenho da empresa. Duas questões básicas foram formuladas para delimitar o problema de pesquisa:

- A força da cultura está significativamente associada ao desempenho organizacional?

- Empresas com cultura forte podem evidenciar melhor desempenho do que aquelas com cultura fraca?

\section{Açóes Metodológicas}

As empresas participantes $(\mathrm{n}=13)$ são do setor têxtil nacional, possuem capital aberto e têm ações negociáveis na Bolsa de Valores de São Paulo (Bovespa). A pesquisa foi conduzida com o corpo gerencial, incluindo diretores, gerentes, chefias e supervisores das diferentes unidades organizacionais: áreas industrial, comercial, administrativa, financeira etc. Foram selecionados para o estudo 478 gerentes, distribuídos em quatro regiões do Brasil: Minas Gerais, São Paulo, Santa Catarina e Rio de Janeiro.

O questionário constituiu o instrumento básico pelo qual foram coletados os dados sobre a cultura organizacional das empresas. Os pontos fortes desta metodologia é que o questionário pode abranger uma população bem maior, envolvendo custo e tempo menores, além de permitir, mais facilmente, comparações entre as diversas organizações pesquisadas.

A estruturação e montagem final do questionário foram divididas em duas partes: a primeira delas consistindo em informações que abrangiam aspectos relacionados aos respondentes, como idade, sexo, tempo de casa e cargo ocupado; a segunda constou de um conjunto de 24 proposições, capazes de gerar perfis que representassem diferentes padrões culturais da organização, ou seja, a cultura grupal, a inovativa, a racional e a hierárquica. Cada uma das proposições foi analisada e respondida com a utilização de uma escala do tipo Likert com cinco pontos, na qual 1 significa nunca ocorre; 2 , ocorre raramente; 3 , ocasionalmente; 4 , freqüentemente; 5 , sempre ocorre. 
A seqüência das proposições no instrumento obedeceu a uma distribuição aleatória. Também foi incluída uma questão aberta, reservada para o respondente emitir qualquer opinião a respeito da organização ou fazer as complementações que julgasse necessárias.

Com o objetivo de corrigir possíveis falhas que pudessem levar a erros de interpretação e entendimento nas perguntas formuladas, foi realizado um pré-teste do questionário junto a 35 alunos do Curso de Pós-Graduação em Administração. Este grupo foi escolhido por ser constituído de pessoas que, em sua maioria, pertenciam a empresas nas quais exerciam cargos de chefia ou gerência.

O questionário autopreenchível e sem necessidade de identificação individual foi enviado aos respondentes e devolvido ao pesquisador pelo correio. A taxa de retorno, igual a $83 \%$, foi considerada alta, como evidencia a Tabela 1.

Tabela 1: Questionários Coletados Junto às Empresas Participantes

\begin{tabular}{|l|c|c|c|c|c|}
\hline Região & $\begin{array}{c}\text { Empresas } \\
\text { participantes }\end{array}$ & \multicolumn{2}{|c|}{ Questionários } & $\begin{array}{c}\text { Taxa de } \\
\text { Entregues Devolvidos }\end{array}$ & $\begin{array}{c}\text { Prazo médio } \\
\text { de } \\
\text { devolução } \\
\text { (em dias) }\end{array}$ \\
\hline $\begin{array}{l}\text { Belo } \\
\text { Horizonte }\end{array}$ & 3 & 140 & 120 & $86 \%$ & 42 \\
\hline São Paulo & 4 & 215 & 164 & $76 \%$ & 40 \\
\hline $\begin{array}{l}\text { Santa } \\
\text { Catarina }\end{array}$ & 4 & 130 & 109 & $75 \%$ & 43 \\
\hline $\begin{array}{l}\text { Rio de } \\
\text { Janeiro }\end{array}$ & 2 & 90 & 85 & $95 \%$ & 53 \\
\hline Total & 13 & 575 & 478 & $83 \%$ & 44,5 \\
\hline
\end{tabular}

\section{Mensuração do Desempenho Organizaional}

A variável desempenho organizacional exigiu análise e estudo muito criteriosos, para que se pudesse escolher a metodologia mais adequada para operacionalizála. O primeiro passo nessa direção foi definir, neste trabalho, que desempenho organizacional é usado no sentido de desempenho econômico-financeiro da empresa e pode ser mensurado por indicadores contábeis. 
Buscou-se, em algumas das melhores publicações especializadas no assunto, o alicerce para os objetivos que se tinha em mente e optou-se pela abordagem desenvolvida por Matarazzo (1985). O autor emprega a técnica de análise dos índices financeiros (relação entre contas ou grupo de contas das Demonstrações Contábeis), a qual permite elaborar a mensuração do desempenho econômicofinanceiro da empresa. Naturalmente, as causas de uma dada situação devem ser buscadas por outros instrumentos, que aprofundem as conclusões obtidas pelos índices.

Recentemente, houve grande evolução das técnicas de índices devido ao desenvolvimento dos chamados índices-padrões e das técnicas estatísticas de estabelecimento de pesos para os diversos índices. Ambos, neste trabalho, foram incorporados à metodologia da avaliação da variável desempenho organizacional.

Os seguintes passos foram estabelecidos para se chegar a uma avaliação das empresas estudadas:

1) Escolha e cálculo dos índices de desempenho global, conforme relacionados no Quadro 1, os quais foram levantados através de dados extraídos do Balanço e da Demonstração de Resultados das organizações-alvos, referentes aos anos de 1988,1989 e 1990.

2) Identificação da posição relativa de cada índice utilizado em sua respectiva tabela de índice-padrão. Esta última, constituída de nove decis, é elaborada anualmente com base em demonstrativos de aproximadamente 900 empresas do ramo da indústria têxtil.

3) Atribuição a cada índice de um conceito e de uma nota, em função de sua posição relativa aos padrões do setor. Para a avaliação final aplicaram-se os seguintes critérios:

\begin{tabular}{|c|c|}
\hline CONCEITO & NOTA \\
\hline Péssimo, Deficiente & $0-1$ \\
\hline Fraco, Insatisfatório & $2-3$ \\
\hline Razoável & $4-5$ \\
\hline Bom & $6-7$ \\
\hline Ótimo & $8-9$ \\
\hline
\end{tabular}

Exemplificando, o índice de liquidez geral igual a 1,33, está mais próximo do $7^{\circ}$ decil da tabela de índice-padrão. Desta forma, irá receber nota 7.0 (sete) e conceito Bom. 
4) Avaliação global da empresa: supondo-se que foram dados conceitos e notas diferentes para os índices utilizados, qual será a avaliação final? Depende da importância de cada um, ou seja, do peso que se lhes vai atribuir.

\section{Quadro 1: Índices Financeiros Utilizados na Análise do Desempenho Global da Empresa}

\begin{tabular}{|l|c|l|}
\hline \multicolumn{1}{|c|}{ Índice utilizado } & $\begin{array}{c}\text { Aspecto } \\
\text { revelado }\end{array}$ & Fator avaliado \\
\hline $\begin{array}{l}\text { Participação de Capitais de Terceiros } \\
\text { Capitais de Terceiros } \times 100 \\
\text { Patrimônio Líquido }\end{array}$ & $\begin{array}{c}\text { Situação } \\
\text { financeira }\end{array}$ & $\begin{array}{l}\text { Estrutura de } \\
\text { Capital }\end{array}$ \\
\hline $\begin{array}{l}\text { Imobilização do Patrimônio Líquido } \\
\text { Ativo Permanente } \\
\text { Patrimônio Líquido }\end{array}$ & $\begin{array}{c}\text { Situação } \\
\text { financeira }\end{array}$ & $\begin{array}{l}\text { Estrutura de } \\
\text { Capital }\end{array}$ \\
\hline $\begin{array}{l}\text { Liquidez geral } \\
\text { Ativo Circulante + Realizável a Longo Prazo } \\
\text { Passivo Circulante + Exigivel a Longo Prazo }\end{array}$ & $\begin{array}{c}\text { Situação } \\
\text { financeira }\end{array}$ & Liquidez \\
\hline $\begin{array}{l}\text { Liquidez corrente } \\
\text { Ativo Circulante } \\
\text { Passivo Circulante }\end{array}$ & $\begin{array}{c}\text { Situação } \\
\text { financeira }\end{array}$ & Liquidez \\
\hline $\begin{array}{l}\text { Giro do Ativo } \\
\text { Vendas }\end{array}$ & $\begin{array}{c}\text { Situação } \\
\text { econômica }\end{array}$ & Rentabilidade \\
\hline $\begin{array}{l}\text { Ativo Inicial + Ativo Final / } 2 \\
\begin{array}{l}\text { Margem líquida } \\
\text { Lucro Líquido } \times 100\end{array}\end{array}$ & $\begin{array}{c}\text { Situação } \\
\text { Vendas }\end{array}$ & Rentabilidade \\
\hline $\begin{array}{l}\text { Rentabilidade do Patrimônio Líquido } \\
\text { Lucro Líquido }\end{array}$ & Rentabilidade \\
\hline $\begin{array}{l}\text { Patrimônio Líquido Médio } \\
\text { econica }\end{array}$ & \\
\hline
\end{tabular}

Neste trabalho, adotaremos a ponderação, seguida por Matarazzo (1985), resultante de uma abordagem empírica, como em seguida se ilustra. 


\begin{tabular}{|c|c|}
\hline Estrutura de Capital: & 1. Endividamento: 0.70 \\
\hline Peso: 0.40 & 2. Imobilização do PL: 0.30 \\
\hline Liquidez: & 3. Liquidez Geral: 0.30 \\
\hline \multirow[t]{2}{*}{ Peso: 0.20} & 4. Liquidez Corrente: 0.70 \\
\hline & 5. Giro do Ativo: 0.20 \\
\hline Rentabilidade: & 6. Margem Líquida: 0.10 \\
\hline Peso: 0.40 & 7. Rentabilidade do PL: 0.70 \\
\hline
\end{tabular}

A seguinte fórmula foi utilizada para obtenção da nota do desempenho global da empresa.

$$
\mathrm{NGE}=0,40 \mathrm{NE}+0,20 \mathrm{NL}+\mathbf{0 , 4 0} \mathrm{NR} \quad \text { onde, }
$$

$\mathrm{NGE}=$ Nota global da empresa

$\mathrm{NE}=$ Nota em estrutura de capital

$\mathrm{NL}=$ Nota em liquidez

$\mathrm{NR}=$ Nota em rentabilidade

Exemplificando:

\begin{tabular}{|l|l|l|}
\hline Índice & Endividamento & Imobilização do PL \\
\hline Valor & $27 \%$ & $68 \%$ \\
\hline Conceito & Ótimo & Satisfatório \\
\hline Nota & 8.0 & 5.0 \\
\hline Peso & 0.70 & 0.30 \\
\hline
\end{tabular}

A nota atribuída à estrutura de capital será:

$$
\begin{aligned}
& \mathrm{NE}=8.0 \times 0.70+5.0 \times .30=7.1 \\
& \quad \text { Supondo } \mathrm{NL}=8.0 \quad \mathrm{e} \quad \mathrm{NR}=3.2, \quad \text { temos que: } \\
& \mathrm{NGE}=040(7.1)+0.20(8.0)+0.40(3.2)=5.7
\end{aligned}
$$

Conceito $=$ Razoável 
A síntese dos resultados encontrados é mostrada no Quadro 2. As empresas pesquisadas foram agrupadas em dois conjuntos. No grupo I foram incluídas as sete empresas com bom desempenho, ou seja, aquelas que tiveram nota média acima de 4.5 nos três anos analisados; classificaram-se como tendo bom desempenho as empresas A, B, C, D, E, I e L. O grupo II incluiu as seis empresas restantes, identificadas com mau desempenho, ou seja, aquelas que obtiveram notas médias nos três anos consecutivos abaixo de 4.5. Classificaram-se como tendo mau desempenho as empresas F, G, H, J, M e N.

\section{Quadro 2: Análise do Desempenho Global das Empresas Pesquisadas}

\begin{tabular}{|c|c|c|c|}
\hline \multirow[b]{2}{*}{ Empresa } & \multicolumn{3}{|c|}{ Desempenho Global } \\
\hline & Ano 1 & Ano 2 & Ano 3 \\
\hline A & $\begin{array}{l}5,0 \\
\text { Razoável }\end{array}$ & $\begin{array}{l}4,0 \\
\text { Razoável }\end{array}$ & $\begin{array}{l}5,0 \\
\text { Razoável }\end{array}$ \\
\hline B & $\begin{array}{l}6,0 \\
\text { Bom }\end{array}$ & $\begin{array}{l}5,0 \\
\text { Razoável }\end{array}$ & $\begin{array}{l}5,0 \\
\text { Razoável }\end{array}$ \\
\hline $\mathrm{C}$ & $\begin{array}{l}7,0 \\
\text { Bom }\end{array}$ & $\begin{array}{l}6,0 \\
\text { Bom }\end{array}$ & $\begin{array}{l}5,0 \\
\text { Razoável }\end{array}$ \\
\hline $\mathrm{D}$ & $\begin{array}{l}4,0 \\
\text { Razoável }\end{array}$ & $\begin{array}{l}6,0 \\
\text { Bom }\end{array}$ & $\begin{array}{l}4,0 \\
\text { Razoável }\end{array}$ \\
\hline $\mathrm{E}$ & $\begin{array}{l}7,0 \\
\text { Bom } \\
\end{array}$ & $\begin{array}{l}7,0 \\
\text { Bom }\end{array}$ & $\begin{array}{l}5,0 \\
\text { Razoável } \\
\end{array}$ \\
\hline $\mathrm{F}$ & $\begin{array}{l}4,0 \\
\text { Razoável }\end{array}$ & $\begin{array}{l}3,0 \\
\text { Insatisfatório }\end{array}$ & $\begin{array}{l}4,0 \\
\text { Razoável }\end{array}$ \\
\hline G & $\begin{array}{l}5,0 \\
\text { Razoável }\end{array}$ & $\begin{array}{l}4,0 \\
\text { Razoável }\end{array}$ & $\begin{array}{l}3,0 \\
\text { Insatisfatório }\end{array}$ \\
\hline $\mathrm{H}$ & $\begin{array}{l}6,0 \\
\text { Bom }\end{array}$ & $\begin{array}{l}5,0 \\
\text { Razoável } \\
\end{array}$ & $\begin{array}{l}2,0 \\
\text { Insatisfatório }\end{array}$ \\
\hline $\mathrm{I}$ & $\begin{array}{l}6,0 \\
\text { Bom } \\
\end{array}$ & $\begin{array}{l}6,0 \\
\text { Bom }\end{array}$ & $\begin{array}{l}5,0 \\
\text { Razoável } \\
\end{array}$ \\
\hline $\mathrm{J}$ & $\begin{array}{l}5,0 \\
\text { Razoável }\end{array}$ & $\begin{array}{l}5,0 \\
\text { Razoável }\end{array}$ & $\begin{array}{l}2,0 \\
\text { Insatisfatório }\end{array}$ \\
\hline $\mathrm{L}$ & $\begin{array}{l}8,0 \\
\text { Ótimo }\end{array}$ & $\begin{array}{l}7,0 \\
\text { Bom }\end{array}$ & $\begin{array}{l}5,0 \\
\text { Razoável }\end{array}$ \\
\hline $\mathrm{M}$ & $\begin{array}{l}1,0 \\
\text { Deficiente }\end{array}$ & $\begin{array}{l}1,0 \\
\text { Deficiente }\end{array}$ & $\begin{array}{l}1,0 \\
\text { Deficiente }\end{array}$ \\
\hline $\mathrm{N}$ & $\begin{array}{l}6,0 \\
\text { Bom }\end{array}$ & $\begin{array}{l}6,0 \\
\text { Bom }\end{array}$ & $\begin{array}{l}1,0 \\
\text { Deficiente }\end{array}$ \\
\hline
\end{tabular}




\section{Modelo Té́rico para o Estudo da Cultura Organizacional}

O modelo intitulado Competing Value Model tem por certo que as organizações podem ser caracterizadas de acordo com seus traços culturais comuns. Ele se traduz num instrumento eficaz para definir os tipos de cultura organizacional, interpretar os seus atributos e estudar a cultura em termos comparativos. Este arcabouço teórico também é conhecido como Tipologia Cultural de Quinn (Quinn e Kimberly, 1984; Quinn e McGrath, 1985). Como um referencial teórico para o estudo da cultura organizacional, o Competing Value Model representa uma alternativa diferente do enfoque qualitativo, que tem caracterizado a realização da maioria das pesquisas em cultura.

O modelo aceita que as organizações podem ser caracterizadas de acordo com os traços culturais ou dimensões comuns a toda a organização humana. Ele visa a organizar os diferentes padrões de comportamento, valores e crenças compartilhados que definem a cultura de uma empresa. Da justaposição de suas duas principais dimensões emergem quatro tipos culturais que caracterizam a tipologia de Quinn.

A primeira dimensão está relacionada ao enfoque organizacional. Ela pode enfatizar, no sentido micro, desde o bem-estar e desenvolvimento do indivíduo na organização, até o crescimento e o desenvolvimento da organização em si mesma, no sentido macro. Em outras palavras, a ênfase pode refletir, nesta dimensão, desde o ambiente interno até o ambiente externo. A segunda dimensão está relacionada à estrutura organizacional; aborda o controle, a estabilidade, bem como a flexibilidade e a mudança.

O primeiro tipo cultural, no quadrante superior à esquerda, é a cultura grupal. Ela é baseada em normas e valores associados à afiliação. A autoridade aqui flui muito bem, quando ela emana de membros envolvidos no sistema há muito tempo. Enfatiza o desenvolvimento de recursos humanos e a participação dos membros nas tomadas de decisão. Líderes tendem a ser participativos e considerativos, oferecem suporte e facilitam a interação através do trabalho em equipe.

O segundo tipo cultural, no quadrante superior à direita, é a cultura inovativa. Ela é permeada por pressupostos de mudança e flexibilidade. Os fatores chaves para a motivação incluem crescimento, estímulo, diversificação e criatividade na tarefa. Líderes nesta cultura tendem a ser empreendedores e idealistas. Apreciam correr riscos, gostam de prever o futuro e também se preocupam em obter recursos, apoio e imagem externa.

O terceiro tipo cultural, no quadrante inferior à esquerda, é a cultura hierár- 
quica. Ela reflete os valores e normas associados à burocracia. Quinn e Kimberly (1984) observaram que esta cultura é permeada por pressupostos de estabilidade; indivíduos aceitam bem a autoridade que emana de papéis formalmente estabelecidos, de regras e regulamentos impostos. Os fatores de motivação incluem segurança e ordem. Os líderes tendem a ser conservadores e cautelosos; prestam estreita atenção aos problemas de natureza técnica.

O quarto tipo cultural, no quadrante inferior à esquerda, é a cultura racional. Ela é permeada por pressupostos de realização. Muita ênfase é dada à crença de que as recompensas virão quanto maior for o desempenho e os resultados. Os fatores de motivação incluem competição e consecução de resultados pré-estabelecidos. Os líderes tendem a ser diretivos, orientados para o objetivo e estão constantemente fornecendo recursos e encorajando a produtividade.

Cada um dos modelos culturais também reflete uma orientação para o estilo do processo de informação. Na cultura grupal adota-se a informação coletiva, participação e consenso, a fim de se obter o envolvimento das pessoas no processo organizacional. Na cultura inovativa o processo de informação intuitivo (inspiração, idéias novas, criatividade) é adotado para se obter revitalização e inovação organizacionais. Na cultura hierárquica usa-se o processo de informação formal, documentação e regras, para se obter estabilidade e continuidade organizacionais. $\mathrm{Na}$ cultura racional o processo de informação individual, julgamento lógico e senso de direção, busca alcançar melhores resultados organizacionais.

Em cada um dos tipos culturais também estão implícitos valores mais específi$\cos$ (meios/fins). Assim, por exemplo no modelo grupal, coesão e moral são vistos como valores meios para o desenvolvimento dos recursos humanos. No modelo inovativo os valores de flexibilidade e adaptação são tidos como meios para o crescimento e obtenção de apoio externo. No modelo hierárquico a administração da informação e comunicação são os meios principais para se alcançar a estabilidade e o controle. E, finalmente, o modelo racional busca alcançar maior lucro e produtividade através do planejamento e estabelecimento de objetivos.

É importante destacar que cada tipo cultural tem outro perfil que lhe é extremamente oposto. Assim, a cultura grupal, que enfatiza flexibilidade e enfoque interno, contrasta nitidamente com o tipo racional, que tem como valores principais o controle e o direcionamento para o ambiente externo. A cultura inovativa é caracterizada pela flexibilidade e enfoque externo, e tem seu oposto direto no modelo hierárquico, que enfatiza controle e preocupação com o ambiente interno.

As fronteiras comuns a cada sistema cultural também merecem destaque. $\mathrm{O}$ tipo grupal e o inovativo compartilham, no mesmo eixo, valores iguais relativos à flexibilidade. A cultura inovativa e a racional se assemelham com relação à ênfa- 
se dada ao ambiente externo, respondendo às mudanças externas e atuando de forma competitiva no mercado. $\mathrm{O}$ tipo racional e o hierárquico têm seus valores centrados no controle. Finalmente, o modelo hierárquico e a cultura grupal possuem dimensão comum, que é a focalização no ambiente interno. Na Figura 1 a seguir estão representados todos os tipos de cultura expressos pela tipologia de Quinn, suas principais dimensões e atributos.

\section{Hipóteses e Aplicações do Modelo}

Duas hipótese básicas são subjacentes ao modelo apresentado. A primeira delas é que as quatro culturas apresentadas são definidas como tipos ideais na Tipologia de Quinn.

\section{Figura 1: Principais Dimensões do Competing Value Model e os Tipos de Cultura Organizacional}

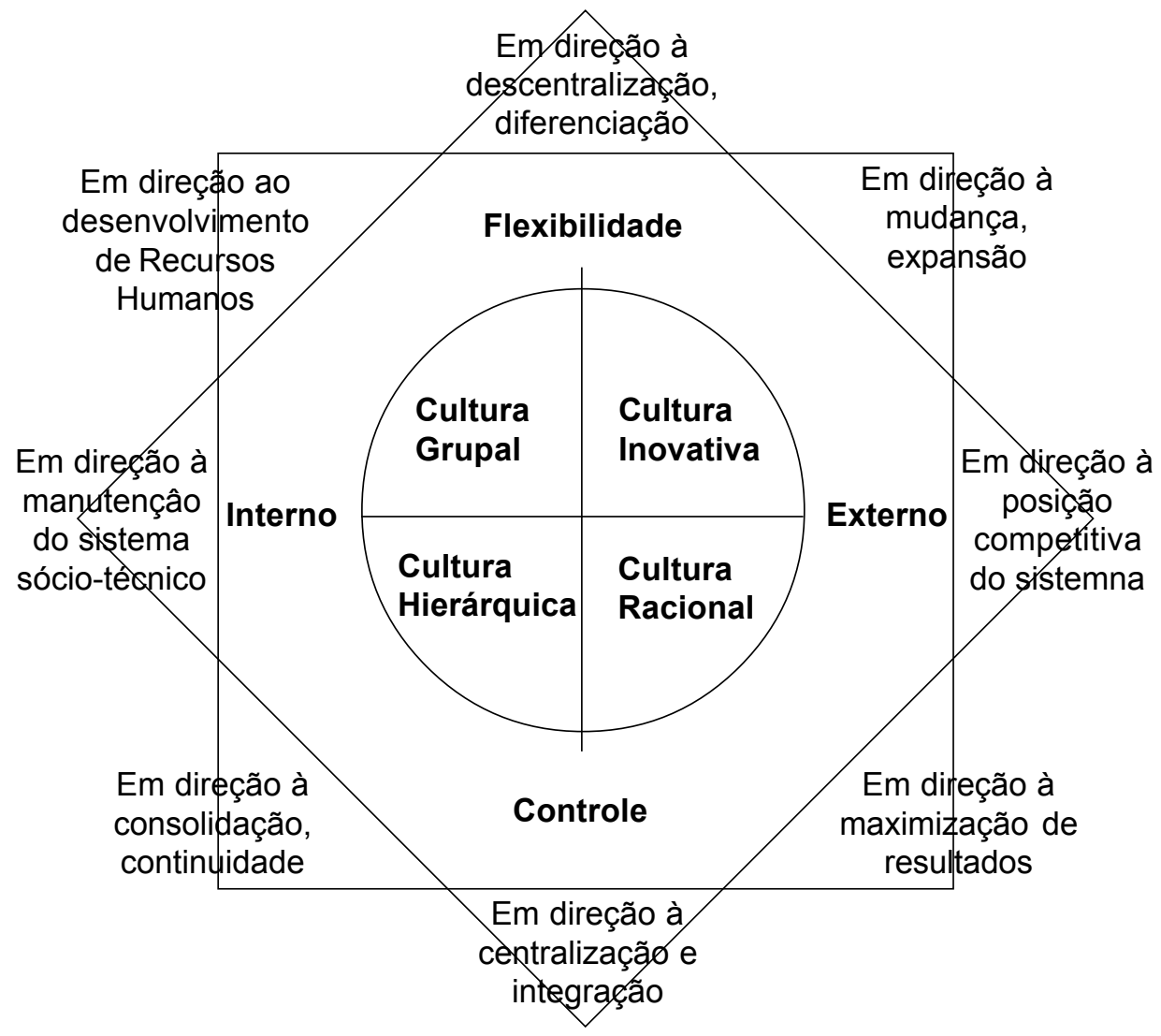


Consistente com o grande número de obras na literatura que apresentam as organizações como fenômenos multiculturais, Gregory (1983) e Quinn e Kimberly (1984) observaram que nenhuma organização reflete, na realidade, uma única cultura. Assim, o modelo identifica combinações de cada tipo cultural, com alguns tipos mais dominantes do que outros. Este variado arranjo de valores ou combinações paradoxais é que dá às organizações culturas diferenciadas, refletidas nas manifestações próprias e particulares de cada uma delas.

A segunda hipótese do modelo é a importância do equilíbrio entre culturas. Quando um quadrante é superenfatizado, uma organização pode tornar-se disfuncional; as forças do quadrante, contrariamente, neste caso, seriam evidenciadas como fraquezas. Por exemplo, muita flexibilidade ou espontaneidade podem levar ao caos; muita ordem e controle podem resultar em rigidez.

\section{Medindo a Força Cultural}

Ao enfocar a questão da cultura, Schein (1984) destaca que a persistência de normas e valores de uma organização pode criar uma cultura total, única e forte; portanto a força da cultura, segundo o autor, pode ser definida em termos de homogeneidade, estabilidade e intensidade das experiências vivenciadas na organização.

Força cultural é definida neste estudo como a extensão em que os valores e crenças que permeiam a organização são ampla e intensamente compartilhados pelos seus membros. O modelo estima que a cultura forte é aquela que mais incorpora as características de todos os quatro tipos culturais. Graficamente é indicada pela área total que é coberta pelos quatro quadrantes da tipologia cultural de Quinn (Quinn e Rohrbaugh, 1981). Maior espaço cultural preenchido deve representar também maior capacidade da empresa poder dar respostas organizacionais ao amplo conjunto de fatores ambientais.

Com a finalidade de evidenciar a força cultural de cada empresa pesquisada, elaborou-se a Tabela 2. O escore médio, por cultura e por instituição, foi calculado somando-se os pontos que as questões associadas a cada cultura receberam na escala Likert (de 1 a 5) e, em seguida, dividiu-se esse resultado por 6 (número de perguntas) e pelo número de respondentes de cada organização. Levou-se em conta o valor médio para que fosse possível a comparação entre as 13 firmas pesquisadas, já que elas não utilizaram igual número de questionários. Na última coluna, tem-se o somatório dos valores encontrados para cada quadrante, representando a força cultural. 
Tabela 2: Valor Médio de cada uma das Culturas com o Respectivo Erro Padrão e Força Cultural por Empresa

\begin{tabular}{|c|c|c|c|}
\hline \multirow[b]{2}{*}{ Empresa } & \multicolumn{3}{|c|}{ Desempenho Global } \\
\hline & Ano 1 & Ano 2 & Ano 3 \\
\hline $\mathrm{A}$ & \begin{tabular}{|l|}
5,0 \\
Razoável \\
\end{tabular} & $\begin{array}{l}4,0 \\
\text { Razoável }\end{array}$ & \begin{tabular}{|l|}
5,0 \\
Razoável
\end{tabular} \\
\hline B & \begin{tabular}{|l|}
6,0 \\
Bom \\
\end{tabular} & $\begin{array}{l}\text { 5,0 } \\
\text { Razoável }\end{array}$ & \begin{tabular}{|l}
5,0 \\
Razoável \\
\end{tabular} \\
\hline $\mathrm{C}$ & $\begin{array}{l}7,0 \\
\text { Bom } \\
\end{array}$ & $\begin{array}{l}6,0 \\
\text { Bom }\end{array}$ & \begin{tabular}{|l}
5,0 \\
Razoável \\
\end{tabular} \\
\hline $\mathrm{D}$ & \begin{tabular}{|l}
4,0 \\
Razoável
\end{tabular} & $\begin{array}{l}6,0 \\
\text { Bom } \\
\end{array}$ & \begin{tabular}{|l}
4,0 \\
Razoável \\
\end{tabular} \\
\hline $\mathrm{E}$ & \begin{tabular}{|l}
7,0 \\
Bom \\
\end{tabular} & $\begin{array}{l}7,0 \\
\text { Bom }\end{array}$ & \begin{tabular}{|l}
5,0 \\
Razoável \\
\end{tabular} \\
\hline $\mathrm{F}$ & $\begin{array}{l}4,0 \\
\text { Razoável } \\
\end{array}$ & $\begin{array}{l}3,0 \\
\text { Insatisfatório }\end{array}$ & $\begin{array}{l}4,0 \\
\text { Razoável } \\
\end{array}$ \\
\hline $\mathrm{G}$ & \begin{tabular}{|l|}
5,0 \\
Razoável
\end{tabular} & $\begin{array}{l}4,0 \\
\text { Razoável }\end{array}$ & $\begin{array}{l}3,0 \\
\text { Insatisfatório }\end{array}$ \\
\hline $\mathrm{H}$ & \begin{tabular}{|l|}
6,0 \\
Bom \\
\end{tabular} & $\begin{array}{l}5,0 \\
\text { Razoável } \\
\end{array}$ & $\begin{array}{l}2,0 \\
\text { Insatisfatório }\end{array}$ \\
\hline I & \begin{tabular}{|l}
6,0 \\
Bom \\
\end{tabular} & $\begin{array}{l}6,0 \\
\text { Bom } \\
\end{array}$ & $\begin{array}{l}5,0 \\
\text { Razoável } \\
\end{array}$ \\
\hline $\mathrm{J}$ & \begin{tabular}{|l}
5,0 \\
Razoável \\
\end{tabular} & $\begin{array}{l}5,0 \\
\text { Razoável }\end{array}$ & $\begin{array}{l}2,0 \\
\text { Insatisfatório }\end{array}$ \\
\hline $\mathrm{L}$ & $\begin{array}{l}8,0 \\
\text { Ótimo } \\
\end{array}$ & $\begin{array}{l}7,0 \\
\text { Bom }\end{array}$ & \begin{tabular}{|l}
5,0 \\
Razoável
\end{tabular} \\
\hline M & \begin{tabular}{|l}
1,0 \\
Deficiente
\end{tabular} & $\begin{array}{l}1,0 \\
\text { Deficiente }\end{array}$ & $\begin{array}{l}1,0 \\
\text { Deficiente }\end{array}$ \\
\hline $\mathrm{N}$ & \begin{tabular}{|l|}
6,0 \\
Bom
\end{tabular} & $\begin{array}{l}6,0 \\
\text { Bom }\end{array}$ & $\begin{array}{l}1,0 \\
\text { Deficiente }\end{array}$ \\
\hline
\end{tabular}

\section{Tratamento Estatístico e Discussão dos Dados}

A análise de clusters (Johnson e Wichern, 1982) foi utilizada para reunir os perfis culturais semelhantes em grupos considerados distintos. A Tabela 3 mostra os dois conjuntos definidos pela técnica estatística aplicada. 
Tabela 3: Caracterização dos Grupos 1 e 2 Obtidos pela Análise de Agrupamentos

\begin{tabular}{|c|c|c|c|}
\hline Tipo cultural & Empresa & Desempenho & Força cultural \\
\hline \multirow[b]{2}{*}{ Perfil do grupo 1} & $\mathrm{~L}$ & Bom & 15,60 \\
\hline & $\mathrm{E}$ & Bom & 15,13 \\
\hline \multirow{4}{*}{ Culturas fortes } & $\mathrm{C}$ & Bom & 14,69 \\
\hline & A & Bom & 14,64 \\
\hline & $\mathrm{F}$ & Mau & 14,37 \\
\hline & B & Bom & 14,26 \\
\hline \multirow{4}{*}{ Perfil do grupo 2} & $\mathrm{~N}$ & Mau & 13,84 \\
\hline & $\mathrm{D}$ & Bom & 13,59 \\
\hline & $\mathrm{M}$ & Mau & 13,29 \\
\hline & I & Bom & 13,14 \\
\hline \multirow{3}{*}{ Culturas fracas } & $\mathrm{H}$ & Mau & 12,59 \\
\hline & $\mathrm{J}$ & Mau & 12,35 \\
\hline & G & Mau & 11,81 \\
\hline
\end{tabular}

Observando-se os dois conjuntos formados pela análise de agrupamentos, podese notar que naquele em que há a predominância das seis empresas com maior força cultural estão também concentradas cinco organizações com bom desempe- 
nho. No segundo grupo, que inclui as sete empresas com menor força cultural, estão concentradas cinco instituições com mau desempenho.

O uso da análise discriminante (Johnson e Wichern, 1982) verificou se as culturas organizacionais realmente discriminavam os dois grupos. O índice de acerto obtido foi de $100 \%$, isto é, os grupos preditos para as empresas coincidiram em sua totalidade com os grupos formados pela análise de agrupamentos. Assim, tem-se um indício de sucesso desta última.

O teste $\mathbf{F}$ utilizado para comparação de variâncias indicou que as variâncias das duas populações poderiam ser consideradas iguais, pois o nível descritivo do teste foi 0.755 .

Foi aplicado o teste T-Student não-pareado (Bussab e Morettin, 1985) para comparar a força cultural média entre as empresas com bom e mau desempenho. A força cultural média das empresas com mau desempenho foi 13.04 e erro padrão de 0.39 ; das empresas com bom desempenho foi 14.43 e erro padrão 0.32 . Feito o teste T-Student para duas populações com mesma variância, observou-se um nível descritivo igual a 0.018 , indicando que há evidências de que a força cultural média das empresas com bom desempenho é maior do que naquelas com mau desempenho (vide Tabela 4).

Tabela 4: Resultado do Teste T-Student para Comparar a Força Cultural Média entre as Empresas com Bom e Mau Desempenho

\begin{tabular}{|c|c|c|c|c|c|}
\hline Desempenho & $\begin{array}{c}\text { Força } \\
\text { cultural } \\
\text { média }\end{array}$ & $\begin{array}{c}\text { Erro } \\
\text { padrão }\end{array}$ & $\begin{array}{c}\text { Número } \\
\text { de } \\
\text { empresas }\end{array}$ & $\begin{array}{c}\text { Estatística } \\
\text { T }\end{array}$ & $\begin{array}{c}\text { Nível } \\
\text { descritivo }\end{array}$ \\
\hline Bom & 14.43 & 0.321 & 7 & $-2,76$ & 0.018 \\
\cline { 1 - 4 } Mau & 13.04 & 0.394 & 6 & & \\
\hline
\end{tabular}

Para se ter uma idéia do grau de associação entre a força cultural, que foi categorizada em forte ou fraca, com base na divisão dos dois grupos feita pela análise de agrupamentos e o desempenho, bom ou mau, calculou-se o coeficiente de contingência padronizado entre as duas variáveis; o valor obtido foi 0.679 , ou seja, há evidências de que existe associação entre as duas variáveis. 
Por último, a análise do coeficiente de correlação linear revelou que há indicações de que existe correlação positiva entre força cultural e desempenho $(r=$ 0.532 para $\mathrm{p}=0.031$ ), ou seja, à medida que aumenta a força cultural, aumenta também o desempenho organizacional.

A correlação entre maior força cultural e melhor desempenho encontra respaldo na hipótese do equilíbrio do modelo utilizado. A pesquisa constatou que os melhores desempenhos foram retratados pelas empresas que também revelaram maior equilíbrio entre os quatro quadrantes da tipologia de Quinn, constituindo, assim, o grupo de maior força cultural. Conforme prevê o modelo, maior espaço cultural preenchido deve representar maior capacidade de a empresa poder dar respostas organizacionais positivas ao amplo conjunto de fatores ambientais que com ela interagem.

A ênfase exagerada em alguma das formas de cultura, levando a instituição a ignorar as demais, gera o desequilíbrio entre os seus atributos, o que, perigosamente, vai conduzir a empresa aos pontos cegos ou zonas negativas decorrentes dos valores, crenças e premissas adotadas em excesso. Tal situação pode ser ilustrada para cada perfil cultural.

Tomemos como exemplo a cultura grupal que é voltada para o desenvolvimento de recursos humanos e incentivos à busca de mais participação, abertura, envolvimento e preocupação com o moral. O cuidado exagerado em desenvolver e fazer aflorar os traços desta cultura, em detrimento dos demais perfis, pode trazer participação inapropriada, discussões improdutivas, individualismo descontrolado e excesso de permissividade, que vão constituir, portanto, uma zona negativa de atuação.

A cultura inovativa tem seu ponto cego também. No excessivo incentivo ao crescimento, ao dinamismo, à criatividade, à adaptabilidade, à preocupação com inovação e com o ambiente externo, pode ocorrer a anarquia tumultuada, que gera conflitos e hostilidades, respostas antecipadas e imaturas aos problemas externos e o oportunismo político.

A cultura hierárquica, que busca valores de maior consolidação, continuidade e estabilidade, pode levar a aflorar seu lado negativo ou a burocracia congelada, que vai caracterizar-se pelo excesso de controle e comando, de centralização e rigidez, de conformidade com normas, regras e procedimentos.

Finalmente, a cultura racional, que positivamente enfatiza a competitividade, orientação para o lucro, atingimento de metas e produção, pode superenfatizar esses valores e crenças organizacionais e conduzir também para o seu ponto cego. Este se revela na exaustão humana, desgaste, esforço exagerado e opressão. 
Os dados apontados aqui são consistentes também com as pesquisas realizadas por Yeung, Brockbank e Ulrich (1991) e Cameron e Freeman (1990), que desenvolveram estudos mais recentes, utilizando a linha metodológica que foi aplicada nesta investigação.

\section{À Luz das Conclusóes}

Autores como Ouchi (1981), Peters e Waterman (1982), Deal e Kennedy (1982), entre outros, declaram que a força da cultura está associada ao desempenho organizacional: "uma cultura forte tem sido quase sempre a mola propulsora que está atrás das companhias de sucesso" (Deal e Kennedy, 1982, p. 5). Os resultados encontrados com a realização deste estudo empírico, nesta amostra composta de empresas do setor têxtil nacional, vêm confirmar tais afirmações e apontam para duas direções: que a cultura está significativamente associada ao desempenho organizacional; que as empresas com cultura forte evidenciam melhor desempenho.

Cabe lembrar que as conclusões aqui apresentadas foram obtidas adotando-se todo o rigor metodológico possível de ser aplicado. Entretanto há de se reconhecer a presença de fatores limitativos e, portanto, alguns cuidados devem ser levados em conta na interpretação dos dados.

Em primeiro lugar, deixamos aqui registrada a impossibilidade de se atingir toda a população levantada. Assim, a generalização desses resultados para outras organizações do setor têxtil, bem como de outros setores industriais, necessita ser empiricamente testada.

Em segundo, cumpre-nos reforçar que este trabalho lida, antes de tudo, com o corpo gerencial das empresas pesquisadas; portanto todas as conclusões devem ser vistas primariamente do ponto de vista de tais indivíduos.

Em terceiro lugar, fazemos referência às limitações de natureza metodológica deste trabalho na própria forma de mensuração do fenômeno. A técnica quantitativa de coleta de dados empregada, quando associada à qualitativa, pode ampliar a análise e as conclusões de qualquer projeto de pesquisa. Todavia, por razões de tamanho da amostra $(n=478)$, custo e tempo envolvidos, nesta pesquisa utilizouse unicamente o questionário estruturado.

Por último, deve-se considerar a perspectiva de que o desempenho organizacional é um fenômeno multidisciplinar; assim, está sujeito a interferências não somente de uma, mas de diversas variáveis que interagem no processo. Kilmann (1987), 
por exemplo, identifica alguns fatores chaves. A cultura organizacional é tida como um dos elementos mais importantes, por constituir certamente verdadeiro canal para a eficácia e bom desempenho da empresa. Cumpre acrescentar: a capacidade gerencial, a formação de equipes e o sistema de recompensas oferecido ao empregado, entre outros.

Por outro lado, embora circunscritos a certos limites, os dados aqui apresentados apontam para resultados fecundos e ressaltam aspectos importantes no processo de desvendar o universo cultural das organizações.

Finalmente, cabe registrar algumas recomendações de ordem geral:

1) Avançar na compreensão teórica do conceito de cultura organizacional e nas formas de abordagens metodológicas para decifrá-la. Ambos os assuntos são muito polêmicos e controvertidos, podendo gerar enfoques novos e diversificados.

2) Não se deve adotar a postura de ser a pesquisa quantitativa melhor ou pior do que a pesquisa qualitativa e vice-versa. A seleção do melhor método de investigação sobre a cultura organizacional não deve ser fim em si mesmo, mas estratégia do pesquisador para produzir os resultados desejados e alcançar os objetivos estabelecidos para o seu projeto. Desta forma, o uso de metodologias alternativas para a análise do universo cultural deve ser visto como complementar e não como mutuamente excludente.

3) As empresas envolvidas nesta pesquisa devem canalizar seu tempo e esforços no sentido de refletir sobre a realidade de uma cultura mais grupal e participativa.

Reduzir níveis hierárquicos, aumentar as responsabilidades funcionais, atribuindo maior delegação, estimular a descentralização nas áreas mais congestionadas, promover a integração e a rapidez de informações, são caminhos que vão permitir à empresa envolver mais seus funcionários num processo de participação nas suas decisões. Não estamos esquecendo e evidentemente temos em mente que o processo pode ser demorado, tendo em vista a diversidade de nossas empresas em termos de porte, tecnologia, estágio de evolução burocrática, de práticas e política de gestão de recursos humanos, bem como de cultura gerencial. Mesmo assim, o momento exige uma reflexão e pensamento cuidadoso, visando à proposta de atuação no futuro.

4) Os nossos atuais e futuros controladores financeiros, os responsáveis ligados à área de sistemas de informações contábeis e os técnicos especializados em geral, devem vislumbrar o grande desafio inerente às suas funções que define o aspecto técnico-comportamental. A mera decisão de criar controles, efetuar pla- 
nos, automatizar e racionalizar não será suficiente para elevar os indicadores de eficácia de uma empresa aos patamares desejados. Será absolutamente indispensável um trabalho de base, que envolva o entendimento da cultura organizacional e das escalas de valores individuais, para que o precisa mudar não se transforme, naturalmente, em movimento de rejeição e boicote.

\section{ReferênCias Biblográficas}

BUSSAB, W. O.;

MORETTIN, P. A.

Estatística básica. 4. ed. São Paulo : Atual, 1985.

CAMERON, D. S.; FREEMAN, S.

Cultural congruence strength and type. In: ACADEMY OF MANAGEMENT MEETING (1990: Washington, DC) Proceedings ... Washington, DC, 1990.

DEAL, T. E.;

KENNEDY, A. A.

Corporate cultures : the rites and rituals of corporate life. Reading, MA : Addison-Wesley, 1982.

DENISON, D. R.

The climate, culture and effectiveness of work organizations : a study of organizational behavior and financial performance. Michigan, 1982. Thesis (Doctoral) University of Michigan.

GORDON, G. G.

The relationship of corporate culture to industry sector and corporate performance. In: KILMANN, R. H.; SAXTON, M. J.; SERPA, R. (Eds.). Gaining control of the corporate culture. San Francisco : Jossey-Bass, 1985.
GREGORY, K.

Native-view paradigmas : multiple cultures and culture conflicts in organizations. Administrative Science Quarterly, n. 28, p. 359-376, 1983.

JOHNSON, R. A.;

WICHERN, D. W.

Applied multivariate statistical analysis. Englewood Cliffs, NJ : Prentice Hall, 1982.

KILMANN, R. H.

Beyond the quick fix. San Francisco : Jossey-Bass, 1987.

MARTIN, J.;

ANYRTSDISN, V.;

SIEHL, C.

Externally espoused values and the legitimation of financial performance. Stanford : Stanford University, 1988. Working paper.

MATARAZZO, D. C. Análise financeira de balanços : abordagem básica. São Paulo : Atlas, 1985. v.1. v.2.

OUCHI, W. G.

Theory $\mathbf{Z}$ : how American business can meet the Japanese challenge. Reading, MA : Addison-Wesley, 1981. 
PETERS, T. J.;

WATERMAN, R. H.

In search of excellence. New York : Harper \& Row, 1982.

QUINN, R. E.;

KIMBERLY, J. R.

The management of transitions. In: KIMBERLY, J. R.; QUINN, R. E. (Eds.). New futures : the challenge of transition management. New York : Dow Jones-Irwin, 1984.

QUINN, R. E.;

MCGRATH, M. R.

The transformation of organizational cultures : a competing value perspective. In : FROST, P. J. et al. (Eds.). Organizational culture. London: Sage, 1985.

QUINN, R. E.;

ROHRBAUGH, J.

A competing value approach to organizational effectiveness. Public Productivity Review, n. 5, p. 122-140, 1981.
SATHE, V.

Culture and related corporate realities : text, cases, and readings on organizational entry, establishment, and change. Illinois : Richard S. Irwin, 1985.

SCHALL, M. S.

A comunication-rules approach to organizational

Administrative Science Quarterly, n. 28, p. 557-581, 1983.

SCHEIN, E. H.

Coming to a new awareness of organizational culture. Sloan Management Review, n. 25, p. 03-16, 1984.

YEUNG, A.;

BROCKBANK, R. J.;

ULRICH, D.

Organizational culture and human resource practices. In: ACADEMY OF MANAGEMENT MEETING (1991 : Washington, DC). Proceedings... Washington, DC, 1991. 